Thorax 1988;43:931-932

\title{
Retrospective estimation of values for total lung capacity by plethysmography, helium gas dilution, and chest radiography in patients with cystic fibrosis
}

\author{
R CUTRERA, P HELMS
}

From the Respiratory Unit, Hospital for Sick Children, Institute of Child Health, London

ABSTRACT In children with cystic fibrosis, total lung capacity was estimated by helium dilution, plethysmography, and radiography. None of these methods should be used interchangeably as the $95 \%$ confidence intervals for estimating were large at $58-144 \%$ for radiography and $45 \cdot 3-100 \cdot 4 \%$ for helium dilution.

In patients with cystic fibrosis or any obstructive lung disease accurate measurement of the volume of gas in the thorax may be difficult. Measurements of gas dilution by helium washin or nitrogen washout underestimate the true gas volume in the presence of air trapping.

In children with cystic fibrosis, total lung capacity (TLC) measured by the radiographic technique (TLCcxr) has been shown to give values similar to those obtained by helium dilution (TLCHe), although, as might be expected, there is a trend for TLC to be larger with the radiographic technique in the more severely affected children.' The difference between the two measurements is usually interpreted as due to "trapped gas." A further problem is that the plethysmographic technique (TLCpleth) may overestimate true gas volumes in the presence of significant airflow obstruction. ${ }^{2}$ We have compared the measurements of TLC obtained from the three currently available methods used in routine clinical practice.

\section{Methods}

We reviewed all patients with cystic fibrosis whose respiratory function had been tested from October 1979 to March 1986. Patients were selected if measurements of lung volume by body plethysmography and helium dilution had been performed on the same visit with an anterioposterior and a lateral chest radiograph on the same occasion.

Functional residual capacity (FRC) was measured by the closed circuit helium dilution technique and the test completed when a change in helium concentration of less than $1 \%$ was observed for 30 seconds or until five minutes had elapsed. ${ }^{3}$ TLCpleth was measured in a constant volume 6001 body plethysmograph at a panting frequency of $1 \mathrm{~Hz} .^{4} \mathrm{~A}$ single measurement was made by each method.

All lung function variables were expressed as percentages of predicted values. ${ }^{3}$ TLCpleth and RVpleth were related to unpublished reference values from the Brompton Hospital, London. TLCcxr was estimated by the method of Pierce et

Address for correspondence: Dr P Helms, Respiratory Unit, Hospital for Sick Children, London WCIN 3JH. (Reprints will not be available.)

Accepted S May 1988 $a,^{6}$ modified for children. ${ }^{7}$ As the range of thoracic size is large during childhood we drew lines directly along the anterior projection of the vertebral bodies rather than $1 \mathrm{~cm}$ in front. ${ }^{6}$ The thoracic volume and its contained structures were calculated initially on elliptical cross sections, followed by the appropriate corrections for magnification ${ }^{8}$ and adjustments to take into account their cross sectional shapes. We have found from computed tomography of the thorax that the contained structures have cross sectional shapes that are independent of the child's age-namely, ellipse area (EA) $\times$ 1.02 for the heart, EA $\times 0.99$ for abdominal contents, and EA $\times 1.29$ for the spine and paraspinal muscles. Thoracic cross sectional shape gradually becomes less elliptical with growth $\left(E A \times(0.04 \times\right.$ age in years $+1 \cdot 10){ }^{7}$

The specific gravity of the lung is about 1.08 , so its wet weight should be close to its degassed displacement volume. The original data of Stowens on wet lung weight and body length from 30000 necropsies on children' are described by the equation: wet lung weight in grams $=0.036 \times$ length $\mathrm{cm}^{1.911}$ over the range $50-170 \mathrm{~cm}$ body length. As all our chest radiographs were obtained routinely an upward correction of 4.5\% was made to allow for failure to inspire fully to TLC, as suggested by Crapo et al. ${ }^{10}$

\section{Recoults}

Forty eight children ( 34 boys, 14 girls) provided 70 sets of data. Mean FEV, was 70\% pred (range 20-129\%) and TLCpleth $112 \%$ (80-140\%). The relationships of TLC measured by the three different methods are shown in table 1.

For 16 children who had measurements made on two occasions we calculated the reproducibility of TLCoxr and TLCHe with respect to TLCpleth by subtracting the percentage difference on occasion 2 from that on occasion 1 . If the relation between TLCHe and TLCpleth had remained the samo-that is, the proportion of "trapped gas" had not altered-the difference would be zero; if "trapped gas" had increased the difference would be negative. When these differences were compared there was a greater repeatability "error" for the radiographic technique (table 2).

\section{Discusion}

In cystic fibrosis, like any chronic obstructive lung disease, TLCHe would be expected to underestimate TLCpleth as a result of "gas trapping."

The error inherent in estimating TLCpleth from TLCcxr was large (table 1). This could have been due to the effects of the disease on both estimates of TLC. Overestimation by plethysmography would be expected in the presence of moderate to severe airflow obstruction ${ }^{2}$ and overestimation 
Table 1 Relation between radiographic and helium total lung capacity (TLC) expressed as a percentage of plethysmographic TLC (TLCpleth)

\begin{tabular}{|c|c|c|}
\hline & $\begin{array}{l}\text { Radiographic } \\
\text { TLC }\end{array}$ & $\begin{array}{l}\text { Helium } \\
\text { TLC }\end{array}$ \\
\hline $\begin{array}{l}\text { Range of absolute } \\
\text { volumes (ml) } \\
\text { Value as \% of TLCpleth (bias) } \\
\text { Mean } \\
\text { Range } \\
\text { Standard deviation of difference }\end{array}$ & $\begin{array}{l}1833 \text { to } 6735 \\
97 \cdot 4 \\
58-144 \\
16.9\end{array}$ & $\begin{array}{l}1418 \text { to } 5457 \\
79 \cdot 9 \\
45-100 \\
12 \cdot 8\end{array}$ \\
\hline
\end{tabular}

by the radiographic technique could result from an increased tissue and blood volume. It is clear from our data that it would be inappropriate to view any of the three techniques as interchangeable because of the wide confidence intervals of their differences (table 1).

Our data were gathered retrospectively, the criteria for selection being the availability of all three investigations within 24 hours. Over the period of the study equipment and methods for obtaining chest radiographs and performing lung function tests did not change. All except one child were over 7 years and all were well used to carrying out lung function tests. Previous studies validating the radiographic technique have been performed prospectively and, although it may be possible to improve the accuracy of the technique by applying the more rigorous measurement conditions of the lung function laboratory, such an approach is unlikely to find favour in a busy imaging department.

The discrepancies between TLCpleth and TLCcxr and the unpredictable nature of their relationship (table 2) led us to reconsider the value of helium dilution measurement of TLC. For a gas dilution technique to measure all the gas within the thorax it might be expected to be necessary to leave the subject attached to the equipment for much longer than the five minutes we allowed. Such an approach, however, is unlikely to be successful, acceptable, or necessary in children as others have found reproducible and stable values of TLCHe over shorter times than we used. ${ }^{3}$ This difference between children and adults is likely to be due to higher basal specific ventilation in children ${ }^{5}$ and additional stimulation to ventilation resulting from the relatively large equipment dead space. It could be argued that the gas dilution volume, as we measured it, is more clinically relevant as it identifies the volume of thoracic gas that is being effectively ventilated.

As plethysmography may be inaccurate in the presence of
Table 2 Repeatability of difference between radiographic and $\frac{5}{5}$ helium total lung capacity $(T L C)$ and plethysmographic $T L C$ in 16 subjects studied on two occasions

\begin{tabular}{|c|c|c|}
\hline & $\begin{array}{l}\text { Radiographic } \\
\text { TLC }\end{array}$ & $\begin{array}{l}\text { Helium } \\
T L C\end{array}$ \\
\hline $\begin{array}{l}\text { Difference between } \\
\text { measurements \% } \\
\text { Mean } \\
\text { Range } \\
\text { Standard deviation of } \\
\text { difference }\end{array}$ & $\begin{array}{l}-6 \cdot 1 \\
-70 \text { to } 45 \\
30\end{array}$ & $\begin{array}{l}-1.4 \\
-11.7 \text { to } 9.9 \\
6.6\end{array}$ \\
\hline
\end{tabular}

significant airflow obstruction ${ }^{2}$ and radiographic measures $\overrightarrow{\vec{\theta}}$ are likely to overestimate true TLC in the presence of $\omega$ parenchymal lung disease, the functional volume measured $\vec{\circ}$ by helium dilution assumes greater importance. So far most $\triangle$ attention has focused on TLCpleth in chronic progressive $\vec{Z}$ diseases such as cystic fibrosis. Our observations suggest that $Z$ more attention should be directed to gas dilution estimates of $\underset{\mathbb{\Phi}}{\stackrel{2}{2}}$ lung volume.

\section{References}

1 Hiller EJ, Kirkpatrick JA, Huang NN Radiographic determina tion of total lung capacity in patients with cystic fibrosis. $J$ Pediatr 1971;78:435-40.

2 Stanescu DC, Rodenstein D, Cauberghs M, Van de Woestijne KP. Failure of body plethysmography in bronchial asthma. $J$ Appl $\overline{\bar{O}}$ Physiol 1982;52:939-48.

3 Greenough A, Loftus BG, Pool J, Price JF. Abnormalities of lung 응 mechanics in young asthmatic subjects. Thorax 1987;42:505-20. \&

4 Cogswell JJ, Hull D, Milner AD, Norman AP, Taylor B. Lung $\overrightarrow{\bar{T}}$ function in childhood: thoracic gas volume and helium function residual capacity measurements in healthy children. $\mathrm{Br} J \mathrm{Dis}$ Chest 1975;69:118-24.

5 Polgar G, Weng TR. The functional development of the res- $\overline{0}$ piratory system. Am Rev Respir Dis 1979;120:625-95.

6 Pierce RJ, Brown DJ, Holmes M, Cumming G, Denison DM. Estimation of lung volumes from chest radiographs using shape information. Thorax 1979;34:726-34.

7 Helms P, Heaf D, Edwards S. How big are the lungs? In: Rudnik J, Kurzawa R, eds. Paediatric respiratory diseases. Rabka, Poland: 3 NRIMMch, 1985:66-74.

8 Bush A, Denison DM. Use of different magnification factors to 윽 calculate radiological lung volumes. Thorax 1986;41:158-9.

9 Stowens D. Pediatric pathology Baltimore: Williams and Wilkins, 음 1966:3.

10 Crapo RO, Montague T, Armstrong J. Inspiratory lung volume achieved on routine chest films. Invest Radiol 1979;14:137-40. 